\title{
Seized Blotters Containing One Regioisomer of 25I-NBOMe
}

\section{Zheng Xiaoyu, Zhao Yanbiao, Yang Hongxian, Gao Lisheng and Zheng Hui}

Institute of Forensic Sciences, Ministry of Public Security, Beijing, PR China

\begin{abstract}
The NBOMe class, mostly represented by the 25I-, 25B- and 25C-NBOMe compounds, is one example among many potentially lethal new psychoactive substances (NPSs) which have emerged in the illegal drugs markets around the world during the last years. Blotters impregnated with NBOMes instead of traditional lysergic acid diethylamide (LSD) have been seized for the first time in mainland China. After proposing the pathway of El-induced fragmentation of 25-I-NBOMe, we also distinguish the possible regioisomers with similar MS results a by the comparison of the fragment ion abundances and the retention time.
\end{abstract}

Keywords: 25I-NBOMe; GC-MS; Lysergic acid diethylamide; Regioisomer

\section{Introduction}

For decades, blotters have been generally impregnated with the potent hallucinogen known as lysergic acid diethylamide (LSD). However, blotters with $\mathrm{N}-2$ methoxybenzyl-substituted phenylethylamine designated as "NBOMes" (or "N-bomb") have been seized in last years around the world. The NBOMes class, mostly represented by the 25I-, 25B- and 25C-NBOMe compounds, is one example among many potentially lethal new psychoactive substances (NPSs) $[1,2]$. It is worthy noticed that, according to the previous reports, the deceased may accidentally ingest 25I-NBOMe as counterfeited LSD which is much more dangerous than LSD $[3,4]$. For this reason, research papers and case reports on these substances are of great interest for the forensic chemistry and toxicology communities [5-7].

Although there were some published reports about the confirmation of these new drugs, the identification of 25I-NBOMe is difficult mainly due to the lack of standards and the proper methodology [8-10]. It is noticeable that there are 3 possible regioisomers with similar MS results (Figure 1). Besides, no experimental case related the confirmation of NBOMes was reported in mainland China to the best of our knowledge.

90 samples of blotters which were suspected of containing LSD were seized last year. We implemented a qualitative method for testing 25-I-NBOMe in blotters by GC-MS, which is applicable to analysis of blotters containing illicit drugs in forensic science laboratories.

\section{Experiment}

\section{Instrumentation}

GC-MS analysis was performed with an Agilent 7890A series gas chromatography system coupled to a $5973 \mathrm{~N}$ series mass selective detector manufactured by Agilent (Santa Clara, CA, USA). The extracts were injected automatically in the split mode (20:1) and the injection volume is $1 \mu \mathrm{L}$. Chromatographic separation was carried out on a DB-5 capillary column $(30 \mathrm{~m} \times 0.25 \mathrm{~mm} \times 0.25 \mu \mathrm{m})$ and helium was used as the carrier gas at a constant flow rate of $1 \mathrm{~mL} / \mathrm{min}$. The initial column temperature was $60^{\circ} \mathrm{C}$, and then increased linearly at a rate of $15^{\circ} \mathrm{C} /$ min to $300^{\circ} \mathrm{C}$, and finally maintained for $15 \mathrm{~min}$ to give a total run time of $31 \mathrm{~min}$. The GC injector and the transfer line were maintained at $280^{\circ} \mathrm{C}$. The spectrometer was operated in electron impact mode (EI). The temperatures of the ion source and quadrupole were $230^{\circ} \mathrm{C}$ and $150^{\circ} \mathrm{C}$, respectively. Ionization energy was set at $70 \mathrm{eV}$ and positive ions were analyzed. Acquisition was carried out in scan mode from 40 to $500 \mathrm{amu}$.

\begin{tabular}{ccc|c}
$\mathbf{R}_{\mathbf{1}}$ & $\mathbf{R}_{\mathbf{2}}$ & $\mathbf{R}_{\mathbf{3}}$ & Compound \\
\hline $\mathrm{OCH}_{3}$ & $\mathrm{H}$ & $\mathrm{H}$ & 25I-NB2OMe \\
$\mathrm{H}$ & $\mathrm{OCH}_{\mathbf{3}}$ & $\mathrm{H}$ & 25I-NB3OMe \\
$\mathrm{H}$ & $\mathrm{H}$ & $\mathrm{OCH}_{\mathbf{3}}$ & 25I-NB4OMe
\end{tabular}<smiles>COc1cc(CCNCc2ccc(Br)c(C)c2Br)c(OC)cc1I</smiles>

Figure 1: Structures of 25I-NBOMe.

\section{Materials and reagents}

The seized blotters printed with pattern such as the avatar of Marilyn Monroe were investigated (Figure 2). Methanol and chloroform (HPLC grade, purity $\geq 99.9 \%$ ) were purchased from Fisher Scientific (USA). Analytical grade tartaric acid (purity $\geq 99.5 \%$ ) and sodium bicarbonate were obtained from sinopharm chemical reagent Co., Ltd (China). Standard LSD and 25I-NBOMe were provided by Sigma-aldrich Company (USA). Deionized water was supplied by reverse diffusion in a Millipore system.

\section{Sample preparation}

Method 1 (named SM1): following the UN recommendations on LSD extraction and testing, four randomly selected stamps (159.14 mg) was soaked in $15 \mathrm{~mL} 1 \%$ tartaric acid and ultrasonicated for $20 \mathrm{~min}$,

${ }^{*}$ Corresponding author: Zheng Hui, Institute of Forensic Sciences, Ministry of Public Security, Beijing 100038, China, Tel: +86-10-63434750; E-mail: xyzheng@ tju.edu.cn

Received February 01, 2018; Accepted February 07, 2018; Published February 14,2018

Citation: Zhang X, Yanbiao Z, Hongxian Y, Lisheng G Hui Z (2018) Seized Blotters Containing One Regioisomer of 25I-NBOMe. J Forensic Biomed 9: 138. doi: 10.4172/2090-2697.1000138

Copyright: ( 2018 Zhang X, et al. This is an open-access article distributed under the terms of the Creative Commons Attribution License, which permits unrestricted use, distribution, and reproduction in any medium, provided the original author and source are credited. 


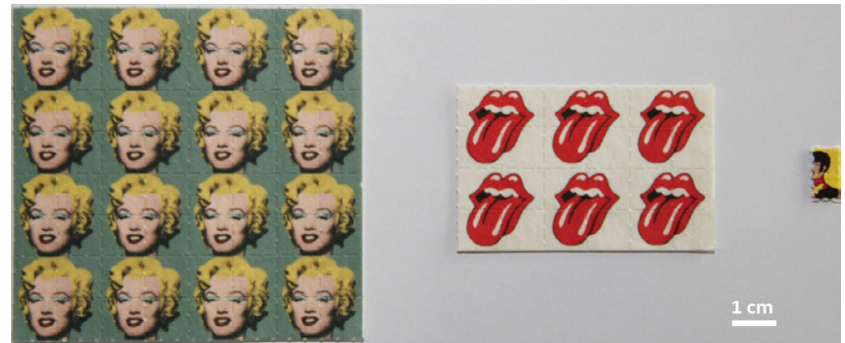

Figure 2: The blotter papers under investigation.

and then extracted for three times with an equal volume of chloroform. After adjusting the $\mathrm{pH}$ of the aqueous phase to be alkaline ( $\mathrm{pH}=8.2$ ) with $1 \mathrm{~N} \mathrm{NaHCO}, 15 \mathrm{~mL}$ chloroform was used to extract for three times again. Followed by filtrated and concentrated by centrifugation white crystal was obtained and dissolved by methanol. $1 \mathrm{~mL}$ extract was added into a vial for gas chromatography-mass spectroscopy (GC-MS) analysis.

Method 2 (named SM2): Another four randomly selected stamps $(158.96 \mathrm{mg}$ ) was submerged in $1 \mathrm{~mL}$ methanol and extracted for $30 \mathrm{~min}$ in an ultrasonic bath. And then the extract was examined by GC-MS.

\section{Results and Discussion}

According to the confession of the suspect, the effective drug ingredient was proposed to be LSD. And then the identification of the compound was performance by a comparison of the mass spectrum and retention time of the extract with those of the pure reference material. As shown in Figure 3, no peak corresponding to LSD exists in the total ion chromatogram (TIC) of the extract at the retention time of 20.93 $\mathrm{min}$. By comparing with the curve of $0.002 \mathrm{mg} / \mathrm{mL}$ LSD and the extract, the existence of LSD in the investigated blotter was excluded.

Figure 4 shows the GC-MS mass spectrum of the ingredient at the retention time (RT) of $17.27 \mathrm{~min}$. The peaks in the mass spectrum were identified by carefully comparing the underlying mass spectra reported in the literatures [11]. The peak corresponding to the molecular ion, $\mathrm{M}=427$ was contained in the spectrum, though the intensity is very low, which is common in phenethylamines and hinders proper identification of a substance. A relatively intense signal was observed at $\mathrm{m} / \mathrm{z}=396$, which is corresponding to M-31 values. Such ions can be formed by the loss of methoxy radical from the molecule [12]. The dominant peak in mass spectrum was observed at $\mathrm{m} / \mathrm{z}=121$ resulted from three possibilities including the cleavage of the $\mathrm{C}-\mathrm{N}$ bond and the $\mathrm{C}-\mathrm{O}$ bond leading to the formation of 2-methoxybenzylcation [13]. Other peaks at $\mathrm{m} / \mathrm{z}=150$, 91,77 and 65 were also commonly recorded, which were created from common parts of the molecules. The ion observed at $\mathrm{m} / \mathrm{z}=150$ could be an iminium cation formed by the dissociation of the C-I bond and the bond between $\alpha$ - and $\beta$-carbon atoms. Such cleavage is a characteristic feature of the mass spectra of phenylethylamines. The decay of the same bond may also lead to dissociation of $\mathrm{N}$-(methoxybenzyl) methylimine molecule and formation of carbocation observed at $\mathrm{m} / \mathrm{z}=277$. In turn, the ions with $\mathrm{m} / \mathrm{z}=91,77$ and 65 were characteristic for a benzyl ring containing a methyl substituent. Peak at $\mathrm{m} / \mathrm{z}=91$ was a tropylium cation and it was probably formed by the loss of methoxy radical from the predominant ion $\mathrm{m} / \mathrm{z}=121$. Noticeably, the relatively intense signals of $\mathrm{m} / \mathrm{z}=277$ and 248 corresponding to $150+127$ and $121+127$ may be resulted from the existence of I. According to the above analysis, 25I-NBOMe was supposed to be contained in the investigated blotters.

It is noticeable that there are 2 other possible regioisomers with

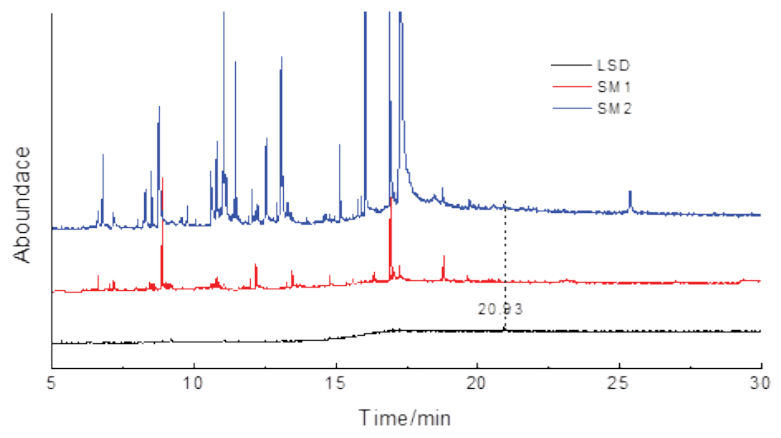

Figure 3: TIC of LSD $(0.002 \mathrm{mg} / \mathrm{mL})$ and the blotters extracted by method 1 (SM1) and method 2 (SM2).

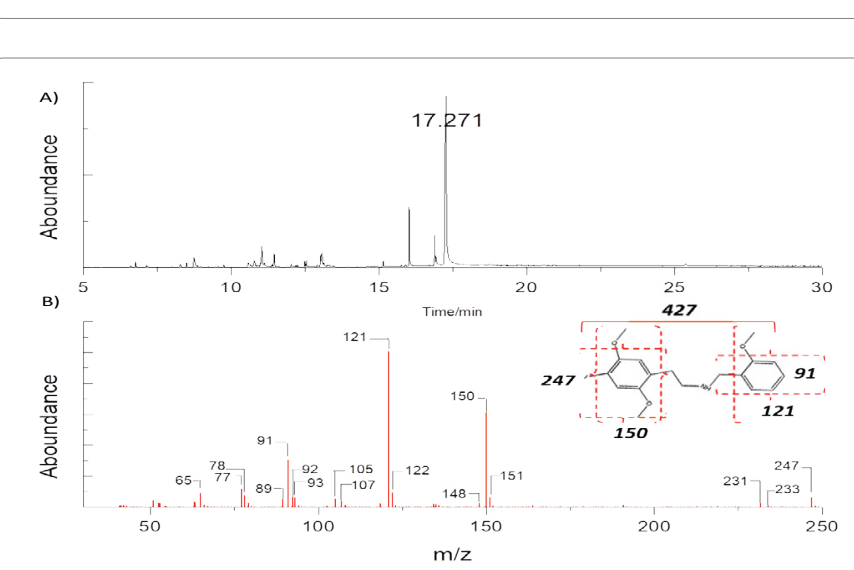

Figure 4: TIC of SM2 (A) and mass spectrum at the RT of $17.271 \mathrm{~min}(\mathrm{~B})$.
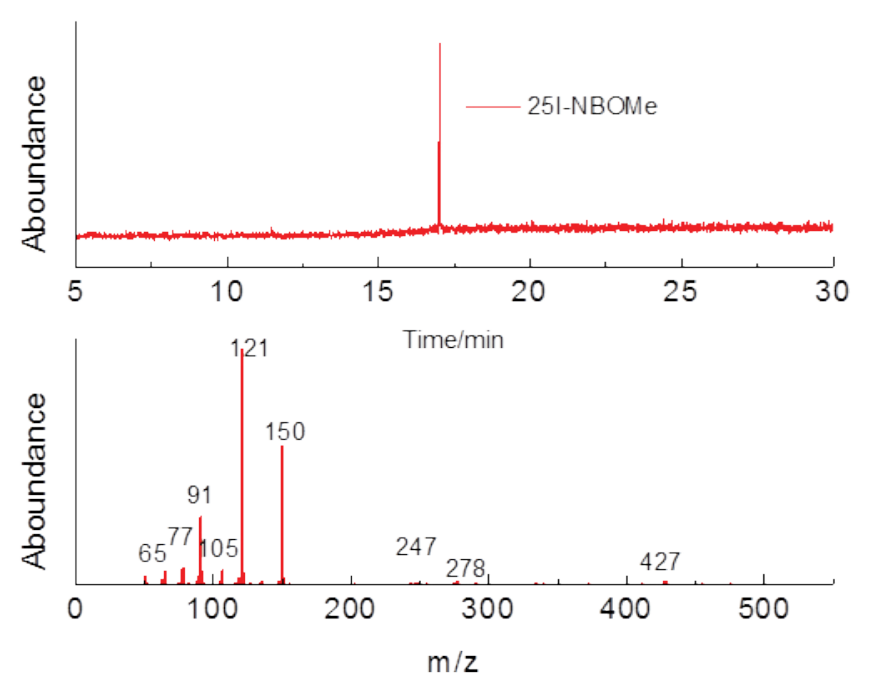

Figure 5: TIC (A) and mass spectrum (B) of 25I-NBOMe.

similar MS results (Figure 1). With this in mind, RT and the ratios of the relative abundance of the fragment ions are very important to certificate the specific structures. For this reason, identification was based upon comparison of the retention time and enhanced product ion scan with reference standards (Figure 5). What's more, the tropylium ion $(\mathrm{m} / \mathrm{z}=91)$ aboundaces were $29 \%$, and the relative abundance of the fragment ion produced at $\mathrm{m} / \mathrm{z} 150$ is $62 \%$, which is consistence with the previous report [14]. 
Citation: Zhang X, Yanbiao Z, Hongxian Y, Lisheng G Hui Z (2018) Seized Blotters Containing One Regioisomer of 25I-NBOMe. J Forensic Biomed 9: 138. doi: 10.4172/2090-2697.1000138

\section{Conclusion}

In this report, the seized blotters contained a class of new psychoactive substance were investigated for the first time showing the evolution of NBOMes in mainland China. Moreover, based on the developed and implemented qualitative method for testing 25-I-NBOMe in blotters by GC-MS, the pathway of EI-induced fragmentation of 25-I-NBOMe was proposed. Additionally, it is worthy for antinarcotics departments to note that NBOMes are becoming potential hallucinogenic drugs consumed in China.

\section{Acknowledgement}

We appreciate the support from the Basic Research Program Exclusive for Central Government-Class Institute of Public Welfare (No.2018JB026).

\section{Conflict of Interest}

There is no conflict of interest.

\section{References}

1. Zawilska JB, Andrzejczak D (2015) Next generation of novel psychoactive substances on the horizon - A complex problem to face. Drug Alcohol Depend 157: $1-17$

2. Papoutsis I, Nikolaou P, Stefanidou M, Spiliopoulou C, Athanaselis S (2015) 25B-NBOMe and its precursor 2C-B: Modern trends and hidden dangers. Forensic Toxicol 33: 1-11.

3. Poklis JL, Devers KG, Arbefeville EF, Pearson JM, Houston E, et al. (2014) Postmortem detection of 25I-NBOMe 2-(4-iodo-2,5-dimethoxyphenyl)-N(2-methoxyphenyl)methyl ethanamine in fluids and tissues determined by high performance liquid chromatography with tandem mass spectrometry from a traumatic death. Forensic Sci Int 234: E14-E20.

4. Ezquiaga I, Grifell M, Galindo L, Martínez L, Palma Á, et al. (2016) 25I-NBOMe: The legal LSD. Eur Psychiatry 33: S72-S73.
5. Lowe LM, Peterson BL, Couper FJ (2015) A case review of the first analytically confirmed 25I-NBOMe-related death in Washington state. J Anal Toxicol 39: 668-671.

6. Walterscheid JP, Phillips GT, Lopez AE, Gonsoulin ML, Chen HH, et al. (2014) Pathological findings in 2 cases of fatal 25I-NBOMe toxicity. Am J Forensic Med Pathol 35: 20-25

7. Kueppers VB, Cooke CT (2015) 25I-NBOMe related death in Australia: A case report. Forensic Sci Int 249: E15-E18.

8. Kyriakou C, Marinelli E, Frati P, Santurro A, Afxentiou M, et al. (2015) NBOMe: New potent hallucinogens - pharmacology, analytical methods, toxicities, fatalities: a review. Eur Rev Med Pharmacol Sci 19: 3270-3281.

9. Grautoff S, Kahler J (2014) Near fatal intoxication with the novel psychoactive substance 25C-NBOMe. Med Klin-Intensivmed Notfallmed 109: 271-275.

10. Nikolaou P, Papoutsis I, Stefanidou M, Spiliopoulou C, Athanaselis S (2015) 2C-I-NBOMe, an "N-bomb" that kills with "Smiles". Toxicological and legislative aspects. Drug Chem Toxicol 38: 113-119.

11. Robayo DAS, Mendez WFG, Ocampo GT, Moreano MR (2016) Analysis of blotter papers employed in the commercialization of new hallucinogenic substances of the 2,5-Dimethoxy-N-(2-methoxybenzyl) phenethylamine series seized in the city of Bogota by applying gas chromatography coupled to a selective mass ion trap detector. J Braz Chem Soc 27: 992-997.

12. Zuba D, Sekula K (2013) Analytical characterization of three hallucinogenic $\mathrm{N}$-(2-methoxy)benzyl derivatives of the $2 \mathrm{C}$-series of phenethylamine drugs. Drug Test Anal 5: 634-645.

13. Zuba D, Sekula K, Buczek A (2013) 25C-NBOMe - New potent hallucinogenic substance identified on the drug market. Forensic Sci Int 227: 7-14.

14. Hays PA, Casale JF (2014) Characterization of eleven 2,5-Dimethoxy-N-(2 methoxybenzyl)-phenethylamine (NBOMe) derivatives and differentiation from their 3-and 4-Methoxybenzyl Analogues -Part II. Microgram Journal 11: 3-22. 